\title{
EAERE Award for the Best Paper Published in Environmental and Resource Economics During 2014
}

\author{
Ian Bateman ${ }^{1}$ - Hassan Benchekroun ${ }^{2}$. \\ Christian Vossler ${ }^{3}$
}

Published online: 28 July 2015

C) Springer Science+Business Media Dordrecht 2015

For several years now the European Association of Environmental and Resource Economists (EAERE) has awarded a prize at its annual conference, generously donated by Springer, for the best paper published within its journal Environmental and Resource Economics (ERE). In determining this award, a panel consisting of the ERE Editor, Ian Bateman, and Co-Editors Hassan Benchekroun and Christian Vossler, evaluates all papers published by the journal over the previous calendar year. We are pleased to announce that the 2014 best paper award goes to:

Robert J. Johnston and Klaus Moeltner, "Meta-Modeling and Benefit Transfer: The Empirical Relevance of Source-Consistency in Welfare Measures".

This excellent and innovative paper applies Bayesian techniques to examine the empirical compatibility of pooling Marshallian and Hicksian welfare estimates within valuation metaanalyses. Using two independent data sets on outdoor recreation and sport fishing activities across multiple locations, the authors demonstrate methods for examining when the pooling of data across welfare measures is defensible. Results reveal the substantial efficiency losses associated with failure to pool measures when appropriate. Taken together, the paper demonstrates a superb level of econometric analysis, delivering a major contribution to the valuation literature and demonstrating the use of techniques which have applicability across a range of metadata contexts.

The committee felt that this was a good year for high quality submissions and five other papers were awarded "Highly Commended" status as follows:

Kenneth J. Arrow and Marcel Priebsch, "Bliss, Catastrophe, and Rational Policy".

$凶 \quad$ Ian Bateman

I.Bateman@uea.ac.uk

1 University of East Anglia, Norwich, UK

2 McGill University, Montreal, Canada

3 University of Tennessee, Knoxville, TN, USA 
Robert J. Johnston and Mahesh Ramachandran "Modeling Spatial Patchiness and Hot Spots in Stated Preference Willingness to Pay".

Jürgen Meyerhoff, Morten Raun Mørkbak and Søren Bøye Olsen, "A Meta-study Investigating the Sources of Protest Behaviour in Stated Preference Surveys".

Halvor Briseid Storrøsten, "Prices Versus Quantities: Technology Choice, Uncertainty and Welfare".

Christian P. Traeger, "A 4-Stated DICE: Quantitatively Addressing Uncertainty Effects in Climate Change".

Each of these papers was identified as representing very substantial contributions to the field of environmental and resource economics and the authors are congratulated for such fine work. Full references to all papers are provided below.

\section{References}

Arrow KJ, Priebsch M (2014) Bliss, catastrophe, and rational policy. Environ Resour Econ 58(4):491-509

Johnston RJ, Moeltner K (2014) Meta-modeling and benefit transfer: the empirical relevance of sourceconsistency in welfare measures. Environ Resour Econ 59(3):337-361

Johnston RJ, Ramachandran M (2014) Modeling spatial patchiness and hot spots in stated preference willingness to pay. Environ Resour Econ 59(3):363-387

Meyerhoff J, Mørkbak MR, Olsen SB (2014) A meta-study investigating the sources of protest behaviour in stated preference surveys. Environ Resour Econ 58(1):35-57

Storrøsten HB (2014) Prices versus quantities: technology choice, uncertainty and welfare. Environ Resour Econ 59(2):275-293

Traeger CP (2014) A 4-stated DICE: quantitatively addressing uncertainty effects in climate change. Environ Resour Econ 59(1):1-37 